\title{
Feedback on Indian NEP (National Education Policy) to Ensure Faculty Parity, Devolution of Power, Function with Manageable Units and Achieve Global Eminence
}

\author{
Adhikarla Suryanarayana Rao \\ Department of Biotechnology, Bharathidasan University, Tiruchirappalli, India \\ Email address: \\ asraobio@gmail.com \\ To cite this article: \\ Adhikarla Suryanarayana Rao. Feedback on Indian NEP (National Education Policy) to Ensure Faculty Parity, Devolution of Power, \\ Function with Manageable Units and Achieve Global Eminence. Higher Education Research. Vol. 6, No. 3, 2021, pp. 63-71. \\ doi: $10.11648 /$ j.her.20210603.12
}

Received: April 26, 2021; Accepted: May 13, 2021; Published: May 21, 2021

\begin{abstract}
To appraise a bulky official document with numerous reforms and huge agenda in a single article is bound to have limitations. Further, in a vast and diverse population differences of opinion are natural. Hence, readers are advised to go through critically the first three references to understand the gargantuan task involved. Subsequently, readers may go through the various responses on different aspects which were appearing in various links given. The present article appraises the issues from overlooked and / or less emphasized angles and suggests regional/central governments and faculty and students friendly approaches to be ultimately successful. Each goal can have a different time dimension. Some useful reforms which can be immediately and easily implemented have been highlighted. Some additional strategies have been suggested for achieving the goals mentioned in the NEP. Lastly, but not the least, author whole heartedly acknowledges the caliber and commitment of all the persons associated in the framing and drafting of NEP. It has been recommended to reflect on the lack of uniformity in power, pay and perks among the various categories of faculty and concurrent and parallel system of education in state and central governments. A mention has been made aobut the various categories of educational institutions, population of India, increasing mandatory working days and hours and resource limitations.
\end{abstract}

Keywords: India, Educational Reforms, Draft \& Revised NEP, Teaching, Research \&Administration, Implementation, Strategies

\section{Introduction}

\subsection{Initial Appraisal}

Readers may keep in mind the following salient points; a) The government has received more than two lakh feedbacks in response to the 484 pages Draft NEP after which the Revised NEP of 66 pages has been prepared and approved [1-3]. These feedbacks are not available on the public domain. However, a most important collective feedback of the three Indian Science Academies based on the whole document is available [4]. A good number of news media have expressed opinions on slected points -not on the basis of whole document. Readers are advised to go through them which are mentioned under NOTE before the list of references. However, one important reference where four eminent persons have expressed their opinions has been mentioned [5]. Readers are advised to go through [6] to compare past and present perspective and state of affairs. b) Author has expressed opinions based on the study of Draft and Revised NEP [1, 2] and collective feedback of the three Indian Science Academies [4] and very long experience in various institutes in the country c) There is absolutely no bias. To avoid motives being attributed or alleging biasness, instead of author dwelling on, readers are advised to go through the links given on their own [under NOTE mentioned in the beginning of the references]. Sincere opinions have been expressed which are felt to contribute to the high accomplishments aspired and nations welfare d) The contributors to the policy are eminent people in the country and have made a commendable effort e) Readers should reflect on the high population and. tremendous heterogeneity 
of the country. Hence, any issue can become controversial and inferences and recommendations can be genuinely different.

\subsection{Few Ground Realities}

Huge population \& tremendous diversity of the country in various parameters -both in general society and in educational system/ institutions pose a serious problem. India has approximately $18 \%$ of the world's population ( 1.4 billion) but has only $2.4 \%$ of world's geographical area and only $4 \%$ of world's water resources. The entire population is presently distributed among 28 states and 9 union territories, 739 districts and about 65 thousand villages. It is herculean task to deal with large and diverse education system with 958 Universities which are further categorised as state, central, private and deemed to be Universities apart from about 40 thousand colleges and 1.5 million schools and huge number of research institutes. So keeping the above parameters in mind any reforms have to be made which is a tough and time taking task [7-14]. [The above figures may vary slightly among different sites.]

\subsection{An outline of Draft and Revised NEP (National Education Policy)}

Draft NEP, 2019 is a bulky document of 484 pages [1] while the revised NEP, 2020 is just of 66 pages [2]. Much smaller revised draft is because of the following differences in compilation: a) Condensation-- Part I (school education) from 153 to 32 plus pages; Part II (higher education) from 137 pages to 16 plus pages; Part III (additional key areas of focus) from 49 to 10 plus pages and Part IV (making it to happen) from 37 pages to just 2 plus pages.; b) long preamble of draft NEP -17 pages- is omitted. Instead an introduction of 3 plus pagesis given; c) 15 appendices in draft NEP are omitted d) list of acronyms and abbreviations reduced from 6 pages to 2 plus pages; e) details of meetings held and list of eminent persons and other bodies consulted during draft NEP are omitted.

In view of the above readers are advised to read both the documents. An important passing mention in revised NEP is that of Covid situation leading to online education. Covid situation was not there during the framing of draft NEP. But now online teaching and exams, virtual conferences and meetings etc have assumed great importance. Hence, a policy may emerge in future in this regard.

\subsection{Aim of this Manuscript}

After a study of $[1,2]$ an attempt has been made to create awareness among the readers from less appraised angles and lay emphasis on performance and accomplishments at the earliest. However, what is puzzling is, members of the three different Indian Science Academies who have given the collective feedback are also eminent people as those who have framed draft NEP. The contents of the 56 page collective feedback [4] gives an impression that many associated with the academies were not consulted / could not participate in framing the draft NEP.

Quoting a current situation to appraise future consequences. Three new laws were made in agriculture sector by the Government of India. No one could anticipate that the farmers would retaliate so seriously attracting even international attention. The problem could not be solved even after two months of protests and many rounds of deliberations-as (situation as on $26^{\text {th }}$ January, 2021) and till now (April 23, 2021. If just for three new reforms, that too in one sector such unimaginable consequences can arise how about numerous reforms proposed in NEP? Difficult to predict how the responses would be across the country over a period of time in future.

It needs to be understood that education sector cannot be viewed in isolation but is very much linked with other sectors -Bureaucracy-Political-Industry-Business-Societal Demands etc. So the entire onus cannot be on the people in the education sector.

\subsection{School Education}

NEP gives lot of emphasis on School education has been given lot of emphasis. Few salient points to be pondered are: a) it would have been useful if a reference is made to the best schools in the world and whether any of their practices are being contemplated. Schools in Finland, some European/Scandinavian countries and from Asia, Japan, Singapore, USA etc are. ranked very high in the world b) School teachers sincerely feel that they do deserve salaries on par with others in the academic sector in view of the huge responsibility placed on them. It is so in some European and American countries c) After $10^{\text {th }}$ (that is in the +4 bracket of 9-12) candidates should have an option to pull out to diversify their career options. Further, the point should be made clear that though exams will be conducted till $10^{\text {th }}$ there will be no detention of the candidates d) Long back there was a proposal to encourage every village to start their own schools-at least up to primary level - and to be managed by the village itself. This proposal has the advantage of teachers being monitored, and parents/ family members being close to children to look after. Particularly, this system is beneficial in ECCE (early child care and education). This proposal may be revived and formalised with due Government assistance e) Home work may be completed by the children right at the school and no burden of it at home. After the school periods are over they may be given a little play time and be back to do their home work right at the school. At home, the home work may not be done by the children but by the parents /family members or tuition teachers. With no burden of home work at home children will be happy at home f) Dealing with many languages in India is both difficult and a sensitive issue. Some specialists in pedagogy say that the children's grasp of elementary things/ basics/fundamentals is best, if taught in mother tongue at least up to $5^{\text {th }}$ class. And up to 10th class also is recommended. Only later, another language medium may be introduced. However, there is a huge population of parents who want to educate their children in English medium right from the beginning. (As NEP stresses attracting 
foreign students English medium, particularly in higher education is inevitable) g) The problem of teacher absenteeism in schools has been mentioned. This is naturally severe in case the number of teachers employed in the school are far less compared to the actual requirement. Absenteeism though highlighted only in schools it maybe there even in colleges and universities. In this context, it is also essential to distinguish between legitimate absenteeism and illegitimate absenteeism. Legitimately, a teacher can avail nearly 6 to 8 months of holidays -cumulatively all categories of legitimate leave eligible. (there can be some variations across the states /institutions/government offices)) So the mandatory working days are much less. Further, the mandatory working hours per day also is less contributing to teachers poor accountability and output. Not to isolate the teachers/educational institutions, nearly six months legitimate leave can also be availed by administrative staff in all Government offices because of which general public are very much affected and not just the education sector. For them also the mandatory working hours per day also are less. It is of immediate need to increase the mandatory working days and mandatory working hours per day. There should be at least 240 working days for students and 240 working days for faculty in view of additional responsibilities they have, at the rate of 40-44 hours per week for better academic performance and global competence. And similarly so in public offices for the welfare of the public, teachers and academicians.

\subsection{Only Unitary Universities}

Presently, India has -in general-a large number of colleges affiliated to the universities causing lot of burden to the universities. The main campuses gets neglected. Document states of gradually removing the colleges affiliation system. Better to disaffiliate colleges to the university at the earliest for better management and performance of universities. There are two possibilities. Colleges becoming autonomous to the extent of conferring degrees or getting affiliated to another apex body like DCE (Directorate of College Education) with DCE being empowered to confer degrees. Former situation is better. States and centre accordingly assign funds. However, an important reform is required in colleges. Presently, professor post/cadre is not there in colleges (barring exceptions) except that of the principal who is considered on par with professor. Teachers in colleges also must be duly promoted to the level of Professor. Whole time teaching is as much a noble duty deserving to raise up to the level of professor. Further, in many colleges offering Masters degrees have a mandatory project work as well which adds to the work load.

\subsection{Publishing Low Quality Papers Either in Paid or Unpaid Journals}

A distinguished academician strongly said that the mandatory prescription of UGC (University Grants Commission, New Delhi) publishing at least one paper for getting a PhD Degree is responsible for the above mentioned. Hence, this prescription should not be there. It makes sense. Another distinguished academician recommended uploading of thesis chapters online $[15,16]$ Because of low funding and also because of candidates working on problems of local relevance it is not possible to publish papers in high quality journals. Even in low quality journals also, candidates experience undue delays and therefore their degree is also delayed. Further, though UGC (University Grants commission)-apex body) insists on only one, the number may vary across the institutes as per the wishes of the research supervisors making the students tenure difficult. In this context another point to be known is, even high quality journals also are paid journals-even charge more heavily-though they are not termed as predatory. Currently three reputed publishers have filed a court case in India demanding blocking of proxy servers to retrieve articles from journals. Hence, a more humane and reasonable approach is let the employer judge the candidates in the interview about the work done rather than insisting on papers either in quantity or quality or be choosy about journals. When there is no money even to conduct the minimum prescribed practicals/experiments as per the course curriculum where is the money for high quality research work? Of course, it is a paradox that huge number of candidates prefer for higher education that too up to $\mathrm{PhD}$ in spite of all the constraints during the tenure of $\mathrm{PhD}$ and unemployment and underemployment realities after completion of $\mathrm{PhD}$. A different paradox here is that many policy makers on the contrary feeling that their number is very less as a percentage of the total who entered higher education comparing the figures with other developed countries. But they do not dwell on the reality of huge 1.4 billion population of the country. Hence, one must carefully evaluate the absolute numbers versus percentages in relation to the manpower requirement Some were/ are of the opinion that bringing large number into higher education is a way of preventing social unrest. As employment opportunities are not there or meagre the youth need to be occupied in some manner and bringing them into higher education is a good way. Both students and parents must be clear about the future prospects of Higher education.

\subsection{Merit Flowing in Other Directions}

NEP emphasises on candidates who are outstanding, Very Good etc. This problem has two dimensions. Very Good / Outstanding /even Good, do not prefer to come -by and large -to teaching/research profession. They go for high profile Central \& State government administrative services, other Government Jobs, MBA's (Master of Business administration), Bank employees, Professional and Technical education like Doctors, Engineers, Computer professionals etc. Only left out will come for teaching and/or research. Of course this does not mean that none from the academic sector are capable of going into the above mentioned services. Some in fact get a change in their mindset later and diversify their careers while some contribute to brain drain to other countries.. 
Even in higher education, there are gross differences. The pay packages of even undergraduate students emerging from IIT's (Indian Institute of Technology) in the employment sector are lucrative and similarly so or more so after an MBA degree from IIM's (Indian Institute of Management). What does a teacher or a researcher in any institutes get Vis a Vis above !?So merit and efforts flows in other directions as above. Even remaining in teaching and research positions, many try to occupy whatever administrative positions possible in their respective institutes there by neglecting teaching and research. The terms -holistic-multidisciplinaryquality-makes sense for the candidates only if they are assured of some decent job after obtaining degrees. That is how they and their parents want education to be. And students and parent should seriously think in this direction.

It should be realised that becoming a knowledge power and super power to reckon with and achieving self sufficiency requires merit flowing in higher and advanced education in different sectors. Hence, all incentives and manpower requirements must be highly rationalised.

\subsection{Central (Federal) Versus States (the Term Federal Is Used in US and Other Countries Instead of Centre/Central)}

How Government wants to view Education-in particular Higher Education? If Government, the way it views the subjects/Departments of defence, atomic energy, space, railways, postal etc and are kept under central Government control, in case education also is viewed in the same manner then the subject of education also should be under central government. But it is not so and the subject is complex and varied. In US -considered as a super power/ knowledge power with maximum Nobel Prizes $(75 \%$ of the total Nobel Prizes) etc - higher education is mostly independent from Federal government regulation and is highly decentralised. It is so in some other countries too. That is how it should be and that is what the 28 states of the country fondly desire. This is a vital point to be acknowledged and such freedom contribute a lot towards unity of the country. Leave all categories of education to the states. As a basic obligation of the Central Government it can give some basal grant to every state towards school \&higher education without any tags. However, a problem in this situation is, different states in the country may follow a different pattern. Hence, all heads of the states should come together and evolve a common policy/ as common policy as possible for the states. Presently there is a scope for every state to function differently and every university within the same state to function differently.

As mentioned above presently the subject is complex and varied. Central Government runs -if not parallel- a large network higher education system. A natural consequence of this is, states being seriously deprived of funds and meritorious manpower consequently getting maligned of less output and performance. To give a rough idea, central government-broadly- runs 54 Central Universities, besides some deemed universities, 20 IIM's (Indian Institute of Management), 23 IIT's (Indian institutes of Technology), 16
AIIMS (All India Institute of Medical Sciences) with 8 more under development, 31 NIT's (National Institute of Technology), 7 IISER's (Indian Institute of Science, Education and Research). Large agricultural net work under the apex body ICAR (Indian Council of Agricultural Research) with 65 research institutions besides 30 plus other centres and four Deemed universities and 38 research institutes under the apex body of CSIR (Council for Scientific and Industrial Research). These 38 institutes have been amalgamated into a degree conferring body AcSIR (Academy of Scientific \& Innovative Research) resulting in a large flow of $\mathrm{PhD}$ students getting registered here. Even ICAR can think in the above manner in future. Students and candidates as faculty are happy to go into the above as they have far better infrastructure and funds and collaborative arrangements while state universities are seriously deprived. There are also many institutes under DST (Department of Science \& technology), DBT (Department of biotechnology) etc. Apart from the above there are many institutes of eminence under the patronage of central government. So who can/should be expected to reach world class or get Nobel Prizes? From the above types of institutes or state institutes? [17-26].

The above process of expansion is not said to be completed. It is evident that from the time of initial establishment, that the above categories of institutes over a period of time have increased. Every state in future would assert to get an institute of the above categories. So a future scenario can be, as many IIT's, IIM's, AIIMS, IISER's, central universities etc as many states and union territories As on today 28 states and 9 union territories. Even then it can be said as skewed distribution. Because, the population of states vary a lot. If a state has one institute of the above category, another state with 5 times more population should have 5 times more number of institute of the above mentioned categories. That is how future assertion can be. In any case the above expansion is not yet completed.

In spite of large education network under central government the central government has made the subject of higher education for states as "concurrent " which means that states do not have full control of the higher education but should follow the mandates and requirements of the central government. In the context of the NEP this aspect apparently is more complicated. All states want heart in heart full control of higher education in their control and not under concurrent list. Any concurrency may be reduced to a bare minimum. A crucial aspect for both central and states institutes is funding and its allocation under different items of budget. It is felt -in general -that the money allocated is sufficient at the most for salaries, maintenance and pensions with very little left for giving hands on experience to students and for carrying out quality research.

\subsection{Concept of Multidisciplinary}

The term "Multi disciplinary" is understood little differently by people. Presently, is it not multi-disciplinary? Take any university or even a college -General, Professional 
or Technical -they all have so many departments and offer courses and/or degrees in many disciplines. In many of these there are departments of arts, humanities, general science apart from numerous departments/ subjects relevant to the concerned professional and technical programs. (Many institutes mentioned under the caption number 1.9 above have been categorised as multidisciplinary). What NEP says is to abolish the present professional and technical universities etc and bring the different faculties -agriculture, medicine, engineering, general science etc -all under one roof. (This recommendation apparently is for the central/state universities). Well, historically speaking, It was so for a long time. Medical college, engineering college, agricultural college etc along with general science and arts subjects were under one roof. At some point, the then eminent academicians and think tanks and naturally with government consent, separated the faculties and proposed specialised universities and that is how specialised universities like agricultural universities etc were carved out from their respective parental general universities. Their vision is right and is still valid. Knowledge and people pursuing knowledge expanded so much and so the principle of "growth followed by division" had to take place. And this process continued and is still continuing and many are at it putting all their efforts for future. Their ambitions will be shattered if anything happens otherwise. When agricultural universities were separated they constituted veterinary/ animal sciences etc as apart of them. Subsequently, veterinary /animal sciences also got separated into an independent university in addition to separate universities for fisheries and horticulture. The above process is very much in the minds of so many and can go a long way. Theoretically, there is a scope for so many more independent universities of the above mentioned categories to be carved out/formed In fact many are aspiring for that. Another important factor is the skewed distribution of the above mentioned universities across the country in the 28 states. Further, there are specific universities for law, medicine, languages, marine sciences, fisheries, horticulture etc. Hence, many states are thinking in this direction.

Hence, each apex body related to professional and technical education like ICAR (Indian council for Agricultural Research), ICMR (Indian council for Medical Research) / MCI (Medical Council of India) / AICTE (All India Council for Technical Education) / VCI (Veterinary Council of India) / BCI (Bar Council of India) etc should come out with separate policy documents of at least 30-40 pages. In view of their importance definitely many reforms and suggestions will be required. Take the task of feeding 140 crore (1.4 billion) people -still growing-. Naturally, the policy of agriculture and animal husbandry requires a greater elaboration of its policies. Similarly, health care for all the above. Hence, there is a need to redraft the policies in professional and technical education and legal education etc. The present documents are felt as making only a passing mention in spite of the high magnitude of the tasks of professional and technical education. Hence, each apex body related to professional and technical education mentioned above should come out with separate policy documents of at least 30-40 pages or even more. In view of their cardinal importance definitely a detailed separate documents are required for every professional and technical education. BCI has been mentioned because millions of cases are pending for a long time in courts at different levels. Hence, the noble concept of "Justice delayed is Justice denied" cannot be followed in spirit. Hence, it needs to be reflected as to how this situation can be alleviated.

There can be drawbacks in the concept of multidisciplinary as per NEP. To have disciplines A to $\mathrm{Z}$ under a single roof as per NEP, is not probably advisable as it is quite some time since specialised universities are running. Further, students law and order problems, friction and rivalries among faculty and severe competition for the administrative posts are likely to be serious apart from the task of management, distribution of funds etcSuch a size is highly unwieldy. Further, it is felt by and large and even by all, that the boss (es) of professional and technical education-at all levels -- should be from their respective professions and disciplines. This is not possible in the present NEP concept of having all disciplines under one roof.

\section{Over Emphasis on Research and Neglect of Teaching}

Teachers even those who are capable teaching are grossly ignoring teaching in view of it not being considered for any evaluation and recognition but everything is decided on the basis of research credentials. Rolling out students with no depth in the knowledge of the subject in which they are specialising do not deliver the goods either for teaching or for research. Hence, making them outstanding is simply not possible. Moreover there is something like an inner aptitude for a person. Say, after MBBS-basic degree for becoming a doctor - not all opt to become practicing surgeons ! In the same manner not all opt or need to opt for research. Many may opt for teaching. What is wrong in some opting for whole time teaching? And teaching is cardinal and indispensable. So no point in relegating teaching at any level or those devoted to teaching for their assessment. Students should get an adequate exposure to the course work for adequate number of semesters. Without having a disciplinary depth expecting them to become great academicians in future is illusive.

Colleges should give disciplinary depth and good hands on experience in the practical syllabus as per the curriculum. (Unlike in the developed west India historically has a large college system with vast number of colleges-nearly 40 thousand (private plus Government combined) most of which are affiliated to universities. So here teaching is $100 \%$ indispensable. In fact this is one of the primary aims and responsibilities in universities as well, apart from research as there is considerable course work in all programs. Accordingly, workload need to be optimized and candidates assessed. Emphasizing so much on research without any 
depth of knowledge in the concerned subject cannot produce any creative individuals. Without disciplinary depth what big breakthroughs and innovations they are going to make in future? Gross neglect of teaching is the main culprit of low quality of teaching and rolling out of students with poor knowledge in the concerned subject. And this gross neglect is because of teaching activity not being duly regarded and rewarded. Long back I read in "Nature" journal (unfortunately unable to trace the reference) a faculty was removed from the services for grossly neglecting the primary responsibility of teaching and getting himself preoccupied with embellishing his curriculum vitae. This has brought disrepute to the institution and he was dismissed from the services. That is how it should be, What to tell in case if the person has neglected teaching and also doesn't / cannot have quality research either?

\section{World Class Universities}

The lament of India not having a single world class university and hence its need was mooted as early as in 1994 [27]. Subsequently, the debate on the establishment of National Science University continued for quite some time during which eminent people from the cross section of the country had expressed their opinions. In this process many problems plaguing the higher education have surfaced. NEP aims at building many world class institutes. Hence, a different thinking is required for this ambition to be achieved at least to some extent and at an earlier date. Is it possible for us to excel the existing top ranking Universities in the world in Europe, North America etc??In how much time it is possible if not to excel at least to become near to them?? If not to excel them at least to raise the present standard to high levels at an early date and become institutes of greater global recognition, a promising strategy is to privatize the present institutes which have already acquired sufficient reputation, infrastructure and possess eminent faculty. Reputed private entrepreneurs /corporates may be given this task who will definitely further raise their standards to make them achieve goals faster, more innovative and useful to them, to the nation and even for the world for a long time to come. They can definitely ensure greater recognition to these institutions and financial revenues. It is these institutes under the dynamic leadership of private entrepreneurs can become world class and compete with world class. The chances of they making both useful and exciting discoveries and also getting Nobel prize (s) either for individuals or organisation also will be enhanced. Government should privatize as many as possible. Private people would also offer them a much better deal as they represent a potential for high returns in future working towards their goals. Government may also declare it as a part of "Corporate social Responsibility" and give due tax concessions for them.

\section{Medical Education}

There is no dearth of candidates aspiring to become doctors. However, manpower planning is required here too because of specialisations. This is an era of specialities and super-specialities. Two important points in this regard are: Many patients do not want to go to a Doctor who has just the basic degree of an M. B. B. S. They want to go only to those doctors who has the advanced Post-graduate qualification$\mathrm{MD} / \mathrm{MS}$. Hence, W. H. O recommendation of doctor to population ratio may not satisfy the requirements of the public [28]. There is a severe problem for the doctors in getting into advanced post-graduate courses and that too in their choice of field. Apparently there is a shortage in this regard.

Regarding the quality /improvement of quality there is definitely something to mention. In countries like US the total duration of medical degree/education is much longer than in India. (In India, after 12 years of schooling within another 5.5 years a candidate can become a doctor) Hence, there is a need to seriously reflect on this issue of increasing the duration of medical education. This can be done by admitting the candidates to medical degree at least after two years of duly designed bachelors training. Further, the residential period of being a House surgeon may be increased by an year. Problem of skewed or even highly skewed rural semi urban-urban distribution of doctors needs to be addressed...

\section{Necessary for the Government to Gain Confidence among all Target Groups}

For the Government to get a strong backing from all target groups there is a need to gain confidence and instill optimism immediately/ at the earliest and make all the target groups highly motivated. Following are some measures:

\subsection{Decent and Uniform Pay \& Perks}

a) Uniform pay scales for all faculty-School-CollegeUniversities-Research Institutes. When so much emphasis is given for school education it is only fair that school teachers too get a good /same deal on par with others in colleges, universities and research institutes $b$ ) Uniform retirement age for all. Presently, the retirement age varies from 58 to 65 years $(58,60,62,65)$ in different institutes across the country. This is highly unfair c) Pension system which was there for along time was replaced by another system. Former pension system should be restored After restoring an option be given to the teachers/ faculty. The length of service required for getting full pension should be as minimum as possible and should be uniform everywhere. Further, medical and social security be made uniform c) Rules for availing sabbatical leave vary widely. Rules should be made fair and uniform d) An identical promotion policy to raise in status /cadre should be there. Power in the administration should be duly shared e) Presently faculty at all levels feel that they do not have a due status in the society on par with other sectors. Faculty in academic sector must be duly empowered so that they can have a better status in the society. 


\subsection{Ensure Simple, Credible and Transparent Administration}

Complete freedom to the Principal Investigator (PI) to operate the research grants. PI should be answerable only to the fund granting agency. Respective institute's administration should not interfere in the operation. Respective institutes do get some basal grant for them with every project sanctioned to the Principal Investigator. They may ask for more but should not interfere with the PI's functioning. All administrative procedures in all matters concerning the faculty and students must be simplified at the earliest.

It is essential that funding agencies have a complete coordination. Each funding agency should have access to all details of each and every other funding agency with respect to who all are funded and to what to extent and proposal details. Only then a funding agency can be more rational in funding. All these details should be available on the public domain. Further, all other relevant information must be made available on the public domain..

\subsection{Increasing Infrastructure, Manpower and Other Requirements}

NEP Document discusses about large number of vacancies and shortage in schools and also in institutions at other levels These vacancies may be filled at the earliest. Not only in schools but even in colleges and universities Deportments vary a lot in the number of faculty they have. This must be rationalized and made uniform. Appointment of faculty - in number, cadre and qualifications - must match with the responsibilities of teaching and research in the concerned departments. However, central government should realize that states cannot afford to fund them and hence require due financial assistance. It is a matter of common knowledge that many costly equipment remain highly underutilized. Funding agencies do not keep a track of it and multiple pieces of the same equipment are often sanctioned. Hence, there is a need for "Central Instrumentation Cell" in every institute with duly appointed staff to take care of. Even if one PI or two have a particular equipment this does not serve the requirements of the huge number of students at all levels. Moreover students require a variety of equipment. This facility is of utmost need.

Construction of at least two smart class room in every department of every institute and provision of mikes and projection facilities in other ordinary class rooms. Teaching laboratories must be fully equipped as per the curriculum requirements. This is all the more important to attract International students. Recently, some publishers have filed a case against the use of Proxy servers to retrieve articles published in their journals. Government has responded by saying that it would follow "One nation one subscription policy" and make all journals available to all institutes in the country. This process may be accelerated. Further, to purchase enough copies of standard text books of foreign authors/publishers enough funds may be provided to the libraries. All educational Institutions must have a banking system empowered with foreign transactions without any hitch.

As mentioned above teachers are getting relegated and teaching neglected. It is indispensable that due regards and rewards to everyone who is wholly involved in either teaching or research. If partly involved, due credit should be given to teaching component as well. Work load should be duly optimized

All the above mentioned-5.1 to 5.3 can be easily done at the earliest. This will make all the state governments and all other target groups to support NEP and participate in its further implementation. And they will also enthusiastically participate in other policies of the government as well.

\section{Additional Expansion}

The NEP has come out with numerous reforms and great ambitions. Undoubtedly, further large expansion in education is required as visualised by NEP. Even in 2010 a government official spoke about the need of additional 800-1000 universities and 35, 000 colleges for that decade. The purpose of mentioning the above is to acknowledge the fact that further expansion in education system is required for the large population. In view of many reforms and a different organisation visualised in NEP the further requirement needs to be duly assessed. After fulfilling what is mentioned above “ 5.1-5.3"as a topmost priority all over the country irrespective of state or central government-- the new vision of NEP may then be implemented first in the newly emerging central institutes followed by existing central institutes. This will take quite some time. Afterwards states/state universities may be focussed.

\subsection{Making the Geographical Units Manageable and Fulfilling the Public Aspirations}

Education can be better administered and implemented as envisioned by the NEP and even otherwise if more states are created. USA with just a quarter of India's population has 50 states and Canada with just 3.7 Crore population has 10 states and 3 territories. Indian with 1.4 billion people has only 28 states and 9 union territories. This angle needs to be seriously reflected. It will also fulfill the aspirations of many sections of the people and favors power and responsibility decentralization /devolution etc and the size of the unit would not be unwieldy at all and easily manageable. In any case it is recommended that a fresh round of collective talks of all the heads of the 28 states in the country be made in this regard.

\subsection{Need for Integrity}

Kudos to the Chairman of the draft NEP 2019, who was honest, bold and exhibited practical wisdom by making two vital statements right in the beginning: a) a complete paragraph has been mentioned about the rampant corruption and its adverse consequences. In the document specifically and feedbacks specifically it has been mentioned with 
reference to school education/teacher education and medical education. However, it should be realized -rather it is already realized - that corruption is very much there and may be even more in sectors other than academic. In the corruption perception index, India has been ranked $80^{\text {th }}$ among 180 countries in the world. Even UN (united nations) documents while stating that corruption and population are two evils of democracy they mentioned India along with other countries. The popular expression -from cradle to grave-is often used in this context. Academic sector cannot be isolated or remain unaffected. Hence, reforms are required in other sectors too. Document discusses about overhauling/ revamping / restructuring etc. These are very much required in the administrative system - not just related to education sector but general administration concerned with the general public b) another vital statement which chairman has made is by quoting Dr. Ambedkar who has framed the Indian constitution. Quite apt. No reforms will work if people executing them are unfair and incapable and even if there is any lacuna in the reforms system will still be protected if those who execute are fair and capable. So it boils down to getting such people into all sectors. Further, the administrative system should be highly simplified and made transparent.

\section{Conclusions}

Commendable that NEP has given a lot of focus on the foundation - that is school education. However, for the country to become a knowledge power and a super power to reckon with in future, excellence in higher education and advanced education is indispensable. Hence, all the existing apex bodies related to various higher education sectors should critically think and elaborate their policies. Neglecting teaching and those involved in teaching -at all levels of education - is highly counterproductive to the ultimate goals. For the desire to excel or even to be on par with world class institutes teaching should be given cardinal importance. With respect to other reforms may be some lateral thinking and novel strategies are required. It is essential to boost the morale and instill confidence among -academic fraternity (at all levels)-general public-state governments- for working collectively for a long time to come to accomplish the high ambitions. In this context some immediate steps need to be taken and those which can be taken easily have been mentioned.

\section{Note}

(Many news channels were displaying online responses from different quarters. Readers are advised to type the desired words of their choice in Google along with and without the following news channels to get an idea). buisnessstandard, businesstodaycollegdekho, Deccan herald, economic times, finaciallexpress. hindustantimes, Indianexpress, Indiatoday, lievemint, timesofindia, masterspprtal, ndtv, news18, odishatv, PTI, thehindu, thehindubuisnessline, uniinida, wikipedia, worldometers, To aovid any attribution of biasness author has avoided mentioning from these.

\section{References}

[1] Draft national Education Policy 2019 https://www.education.gov.in/sites/upload_files/mhrd/files/Dr aft_NEP_2019_EN_Revised.pdf-484 pages (all inclusive).

[2] National Education Policy 2020 https://www.education.gov.in/sites/upload_files/mhrd/files/NE P_Final_English_0.pdf- 66 pages (all inclüsive).

[3] NEP: More than 2 lakh feedbacks received so far http://www.uniindia.com/news/parliament/nep-more-than-2lakh-suggestions-received-so-far/1796685.html2019.

November 21, Reposted January 12, 2021, United news of India.

[4] Observations on the Draft of national Education Policy-2019. Indian National science Academy (New Delhi), Indian Academy of Sciences (Bengaluru) and National academy of Sciences, India (Allahabad) http://www.dialogue.ias.ac.in/article/20944/observations-onthe-draft-national-education-policy (56 pages).

[5] What do those in the Education sector Think of the Draft NEP ? Wire-August $2^{\text {nd }}, 2019$.

[6] Nature (2015) Science in India. Special Issue, $14^{\text {th }}$ May Vol. 521.

[7] https://www.worldometers.info/geography/largest-countriesin-the-world/.

[8] https://www.worldometers.info/world-population/indiapopulation/.

[9] https://wiki.openstreetmap.org/wiki/Villages_in_India\#.

[10] https://indianexpress.com/article/india/28-states-9-unionterritories-here-is-the-new-map-of-india-6099663/.

[11] https://wiki.openstreetmap.org/wiki/Districts_in_India

[12] https://www.ugc.ac.in/oldpdf/consolidated $\% 201$ list $\% 20 \mathrm{of} \% 20 \mathrm{a}$ $11 \% 20$ universities.pdf.

[13] https://www.statista.com/statistics/660862/higher-educationinstitutions-bytype-india/.

[14] https://timesofindia.indiatimes.com/india/india-has-3-timesmore-schools-than-china-but-they-are-amess/articleshow/68616961.cms.

[15] https://journosdiary.com/2019/06/11/ugc-phd-thesis-paperrule-balaram/.

[16] https://www.scholarify.in/no-paper-publication-prior-to-phdthesis-submission/.

[17] https://www.collegedekho.com/articles/list-of-iim-colleges-inindia-ranking-courses-offered/.

[18] http://www.iiseradmission.in/.

[19] https://www.collegedekho.com/articles/list-of-aiims-collegesin-india/. 
[20] https://www.collegedekho.com/articles/list-of-iit-colleges-inindia-admission-basis-jee-advanced/.

[21] https://www.shiksha.com/b-tech/articles/nits-in-india-blogId20003.

[22] https://www.icar.org.in/node/119.

[23] https://www.csir.res.in/csir-labs.

[24] https://acsir.res.in/.
[25] https://dst.gov.in/autonomous-st-institution.

[26] http://dbtindia.gov.in/about-us/organizationstructure/autonomous-institution.

[27] Current science (Bangalore) (1994) Special Issue on National science University. Vol, 67, p 502-519.

[28] Raman Kumar and Ranbir Pal (2018). India achieves WHO recommended doctor patient ration: A call for paradigm shift in public health discourse. Journal of family medicine and primary care. Vol 7: 841-844. 